\title{
Simulation Analysis of Mastication Motion Laws of Different Texture Foods Based on Finite Element Method
}

\author{
Li Chen ${ }^{\text {a }}$ \\ School of Electrical Engineering, Jilin Engineering Normal University, Changchun130052, China. \\ a flygirl1983@126.com
}

\begin{abstract}
Three typical textures of brittle, elastic and viscous foods were selected, and the mastication was simplified into 3 modes of cutting, pressing and grinding. The optimal mastication mode of each texture was identified according to the material destruction criteria and using the finite element method (FEM). Then the mastication was set with 3 laws of uniform motion, uniform acceleration/deceleration, and uniform jerk. The optimal chewing motion laws of the 3 types of foods were analyzed via FEM. It was found at the mastication time of $0.2 \mathrm{~s}$, the best failure effect of brittle foods was found in uniform acceleration/deceleration under the cutting mode, with the maximum principal stress of $6.366 \mathrm{MPa}$. The best failure of elastic foods was found during uniform acceleration/deceleration under the grinding mode, with the maximum shear stress of $15.644 \mathrm{MPa}$. The best failure effect of viscous foods was observed during uniform acceleration/deceleration under the grinding mode, with the maximum von Mises stress of $13.863 \mathrm{MPa}$. These findings will modestly guide the investigations into the motion laws of mastication robots.
\end{abstract}

Keywords: Mastication mode, Mastication motion laws, Material failure criteria.

\section{Introduction}

Owing to the subjectivity and instability, the sensory evaluation methods of food textures have been basically replaced by instrumental methods. Previously, texture analyzers were commonly used for simulation and measurement [1], but were limited by the singleness of probe movement mode and the inability to reproduce the complex motion laws of the real mandible mastication. Later, mastication robots have gradually emerged. Sun designed and developed a mastication simulation system similar to the human mastication system and used it to evaluate food texture [2]. Xie simulated human mastication and developed a food mastication simulator capable of automatic regulation [3]. Based on the oral environment and mastication behaviors, Liu developed a set of simulated mastication devices and used to precisely evaluate beef tenderness grades [4]. Christian M et al. developed a horizontal/vertical biaxial mastication simulation device [5].

These mastication robots are all capable of evaluating food textures, but the mandible motion laws have not been systematically analyzed, which should be further explored. The reason is that mandible motion laws theoretically underlie the motion laws auto-regulation of mastication robots when masticating different foods. Regarding the complexity of mastication motion laws, the motion laws differ among food textures. The variation of motion laws necessarily leads to the differences in the yield or fracture status of foods before fracturing.

In this study, based on strength theories, we summarized the material failure criteria, and used the finite element method (FEM) to analyze the optimal mastication mode and mastication motion laws of 3 typical food textures, which were brittle, elastic and viscous, respectively. This study underlies the design of mastication robot motion structures.

\section{Material Failure Criteria}

The strength theories in elastoplastic mechanics are focused on the laws of material failure or yield [6]. Here foods were assumed to be continuous, homogeneous and isotropic. Then together with the first, third and fourth strength theories, we judged whether a food material was destroyed by using three criteria.

The maximum tensile stress criterion: The major cause of fracture failure in brittle materials is the maximum tensile stress; regardless of stress status, brittle fracture will occur as long as the maximum 
tensile stress omax at any point of the material reaches the stress limit. The fracture behaviors of brittle foods accord with the maximum tensile stress criterion:

$$
\left[\sigma_{1}, \sigma_{2}, \sigma_{3}\right]_{\max } \leq \sigma_{\mathrm{b}}
$$

where $\sigma_{1}$-- the first principal stress of the material, $\mathrm{MPa}$;

$\sigma_{2}--$ the second principal stress, $\mathrm{MPa}$;

$\sigma_{3}--$ the third principal stress, MPa;

$\sigma_{b}--$ the maximum tensile stress that can be undertaken by the material, $\mathrm{MPa}$;

The Tresca criterion: The major cause of yield in the materials is the maximum shear stress; regardless of stress status, yield failure will occur as long as the maximum shear stress $\tau$ max reaches the limit value of shear stress. The failure behaviors of elastic foods during mastication conform to this criterion:

$$
\tau_{\max }=\frac{\sigma_{1}-\sigma_{3}}{2} \leq \frac{\sigma_{\mathrm{s}}}{2}
$$

where $\sigma_{1}$-- the maximum principal stress of the material, $\mathrm{MPa}$;

$\sigma_{3}$-- the minimum principal stress, $\mathrm{MPa}$;

$\sigma_{\mathrm{s}}--$ the limit shear stress, MPa.

The Mises criterion: The major cause of yield failure in the material is the shape-changed strength ratio; regardless of stress status, yield failure will occur as long as the shape-changed strength ratio at any point of the material reaches the limit value of the unilateral stress status. The mastication failure of strongly viscous or chewy foods can be described by this criterion:

$$
\sqrt{\frac{1}{2}\left[\left(\sigma_{1}-\sigma_{2}\right)^{2}+\left(\sigma_{2}-\sigma_{3}\right)^{2}+\left(\sigma_{3}-\sigma_{1}\right)^{2}\right]} \leq \sigma_{\mathrm{s}}
$$

where $\sigma_{1}$-- the first principal stress of the material, $\mathrm{MPa}$;

$\sigma_{2}--$ the second principal stress, $\mathrm{MPa}$;

$\sigma_{3}--$ the third principal stress, MPa;

$\sigma_{\mathrm{s}}--$ the limit stress of the material during unilateral tension, MPa.

\section{Mastication Motion Laws}

The laws of mastication motion can be simplified into three modes of uniform motion, uniform acceleration/deceleration, and uniform jerk [7-8].

\subsection{Uniform Motion}

When the lower teeth are extruding the food at the velocity $\mathrm{V} 0$, the relative displacement $\mathrm{s}$ between the lower and upper tooth faces is changing with time $t$ as follows:

$$
\mathrm{s}=V_{0} t=\frac{\mathrm{S}_{0}}{\mathrm{~T}_{0}} \mathrm{t} \quad \mathrm{t} \in\left[0, \mathrm{~T}_{0}\right]
$$

where $\mathrm{S}_{0}$-- the sum of relative displacement between the lower and upper tooth faces at the end of the biting activity, mm;

$\mathrm{T}_{0}$-- the total time of biting activity, $\mathrm{s}$.

\subsection{Uniform Acceleration/Deceleration}

The lower teeth move to the upper teeth firstly at uniform acceleration and then at uniform deceleration, until the lower and upper teeth bite together.

The relative displacement $\mathrm{s}$ between the lower and upper tooth faces during the uniform acceleration/deceleration changes with time $\mathrm{t}$ as follows: 


$$
\mathrm{S}=\left\{\begin{array}{lc}
\frac{\mathrm{S}_{0}}{\mathrm{~T}_{0} \mathrm{~T}_{1}} & \mathrm{t} \in\left[0, \mathrm{~T}_{1}\right] \\
\frac{\mathrm{T}_{1} \mathrm{~S}_{0}}{\mathrm{~T}_{0}-\mathrm{T}_{1}}\left(\frac{2}{\mathrm{~T}_{1}} \mathrm{t}-\frac{1}{\mathrm{~T}_{0} \mathrm{~T}_{1}} \mathrm{t}^{2}-1\right) \mathrm{t} \in\left[\mathrm{T}_{1}, \mathrm{~T}_{0}\right]
\end{array}\right.
$$

where $\mathrm{S}_{0}$-- the sum of relative displacement between the lower and upper tooth faces at the end of the biting activity, mm;

$\mathrm{T}_{0}$-- the total time of biting activity, $\mathrm{s}$.

\subsection{Uniform Jerk}

The lower teeth first accelerate at a decreasing acceleration, and then decelerate at an increasing acceleration.

The relative displacement $\mathrm{s}$ between the lower and upper tooth faces during the uniform jerk changes with time $t$ as follows:

$$
\mathrm{S}=\frac{\mathrm{S}_{0}}{\mathrm{~T}_{0}^{2}}\left(3 \mathrm{t}^{2}-\frac{2}{\mathrm{~T}_{0}} \mathrm{t}^{3}\right) \mathrm{t} \in\left[0, \mathrm{~T}_{0}\right]
$$

where $\mathrm{S}_{0}$-- the sum of relative displacement between the lower and upper tooth faces at the end of the biting activity, mm;

$\mathrm{T}_{0}$-- the total time of biting activity, $\mathrm{s}$.

\section{FEM-based Study on Mastication Motion Laws of Different Food Textures}

\subsection{Mastication Motion Laws of Brittle Foods}

The constitutive parameters of the brittle foods were tested [9-10]. The constitutive parameters of the majority of brittle foods are showed in Table 1.

Table 1. Simulation parameters of brittle food materials

\begin{tabular}{cccc}
\hline Elastic modulus (Mpa) & Poisson's ratio & Density $\left(\mathrm{kg} \cdot \mathrm{m}^{-3}\right)$ & Dynamic friction coefficient \\
\hline 20 & 0.35 & 1000 & 0.2 \\
\hline
\end{tabular}

With brittle food boluses $(8 \times 8 \times 1 \mathrm{~mm} 3)$ and the cutting mode, the three-dimensional models of upper and lower incisors were constructed as boundaries by using the reverse engineering technology. The mastication motion process was simulated under the three motion laws separately. According to above equations, the relative displacement between upper and lower tooth faces at the interval of 0.01 $\mathrm{s}$ was calculated, and used to plot the tooth motion orbits. Then the principal stresses under the 3 motion laws were determined. Figure 1 shows the mastication simulation schematic diagram of brittle foods under the cutting mode. Table 2 shows the maximum principal stresses on surfaces of brittle foods under the 3 motion laws.

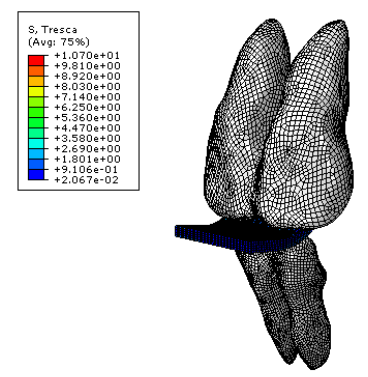

Figure 1. Schematic diagram for simulation of brittle food mastication under the cutting mode 
Table 2. Effects of different motion laws on the cutting performances of brittle foods

\begin{tabular}{|c|c|c|c|}
\hline Motion mode & $\begin{array}{c}S^{\prime} \\
(\mathrm{mm})\end{array}$ & $\begin{array}{l}T_{0} \\
(\mathrm{~s})\end{array}$ & $\begin{array}{c}\sigma_{\max } \\
(\mathrm{Mpa})\end{array}$ \\
\hline Uniform motion & 1.414 & 0.2 & 6.270 \\
\hline Uniform acceleration/deceleration & 1.414 & 0.2 & 6.366 \\
\hline Uniform jerk & 1.414 & 0.2 & 6.316 \\
\hline
\end{tabular}

The surface principal stress of the brittle foods is the largest under the uniform acceleration/deceleration (Table 2), indicating the brittle foods are suitable for mastication at uniform acceleration/deceleration.

\subsection{Mastication Motion Laws of Elastic Foods}

The constitutive parameters of the elastic foods were tested [11- 12]. The constitutive parameters of the majority of elastic foods are showed in Table 3, which were used in the simulations.

Table 3. Simulation parameters of elastic food materials

\begin{tabular}{cccc}
\hline Elastic modulus $(\mathrm{Mpa})$ & Poisson's ratio & Density $\left(\mathrm{kg} \cdot \mathrm{m}^{-3}\right)$ & Dynamic friction coefficient \\
\hline 3.6 & 0.2 & 200 & 0.1 \\
\hline
\end{tabular}

With elastic food boluses $(8 \times 8 \times 1 \mathrm{~mm} 3)$ and the grinding mode, the three-dimensional models of first upper and lower molars were constructed as boundaries by using the reverse engineering technology. The mastication motion process was simulated under the three motion laws separately. According to above equations, the relative displacement between upper and lower tooth faces at the interval of $0.01 \mathrm{~s}$ was calculated, and used to plot the tooth motion orbits. Then the shear stresses under the 3 motion laws were determined. Figure 2 shows the mastication simulation schematic diagram of the elastic foods under the grinding mode. Table 4 shows the maximum shear stress on surfaces of elastic foods under the 3 motion laws.

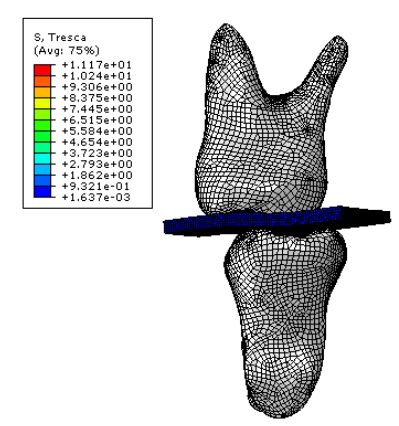

Figure 2. Schematic diagram for simulation of elastic food mastication under the grinding mode

Table 4. Effects of different motion laws on the grinding performances of elastic foods

\begin{tabular}{|c|c|c|c|}
\hline Motion mode & $\begin{array}{c}S^{\prime} \\
(\mathrm{mm})\end{array}$ & $\begin{array}{l}T_{0} \\
\text { (s) }\end{array}$ & $\begin{array}{c}\sigma_{\max } \\
(\mathrm{Mpa})\end{array}$ \\
\hline Uniform motion & 1.414 & 0.2 & 15.491 \\
\hline Uniform acceleration/deceleration & 1.414 & 0.2 & 15.644 \\
\hline Uniform jerk & 1.414 & 0.2 & 15.292 \\
\hline
\end{tabular}

The surface shear stress of the elastic foods is the largest under the motion law of uniform acceleration/deceleration (Table 4), indicating the elastic foods are also suitable for mastication at uniform acceleration/deceleration.

\subsection{Mastication Motion Laws of Viscous Foods}

The constitutive parameters of the viscous foods were tested [13-14]. The constitutive parameters of the majority of viscous foods are showed in Table 5, which were used in the simulations. 
Table 5. Simulation parameters of viscous food materials

\begin{tabular}{cccc}
\hline Elastic modulus $(\mathrm{Mpa})$ & Poisson's ratio & Density $\left(\mathrm{kg} \cdot \mathrm{m}^{-3}\right)$ & Dynamic friction coefficient \\
\hline 16 & 0.3 & 800 & 0.2 \\
\hline
\end{tabular}

With viscous food boluses $(8 \times 8 \times 1 \mathrm{~mm} 3)$ and the grinding mode, the three-dimensional models of the first upper and lower molars were constructed as boundaries by using the reverse engineering technology. The mastication motion process was simulated under the three motion laws separately. According to above equations, the relative displacement between upper and lower tooth faces at the interval of $0.01 \mathrm{~s}$ was calculated, and used to plot the tooth motion orbits. Then the von Mises stresses under the 3 motion laws were determined. Figure 3 shows the mastication simulation schematic diagram of the viscous foods under the grinding mode. Table 6 shows the maximum von Mises stress on surfaces of viscous foods under the 3 motion laws.

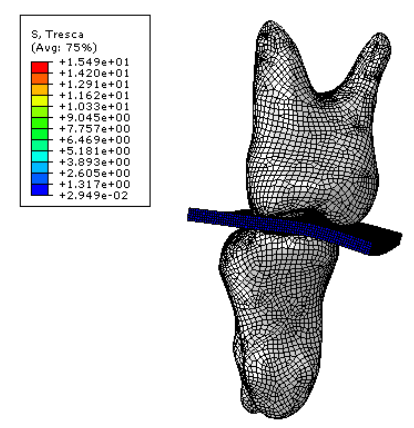

Figure 3. Schematic diagram for simulation of viscous food mastication under the grinding mode

Table 6. Effects of different motion laws on the grinding performances of elastic foods

\begin{tabular}{|c|c|c|c|}
\hline Motion mode & $\begin{array}{c}S^{\prime} \\
(\mathrm{mm})\end{array}$ & $\begin{array}{l}T_{0} \\
(\mathrm{~s})\end{array}$ & $\begin{array}{c}\sigma_{\max } \\
(\mathrm{Mpa})\end{array}$ \\
\hline Uniform motion & 1.414 & 0.2 & 13.788 \\
\hline Uniform acceleration/deceleration & 1.414 & 0.2 & 13.863 \\
\hline Uniform jerk & 1.414 & 0.2 & 13.694 \\
\hline
\end{tabular}

The surface von Mises stress of the viscous foods is the largest under the law of uniform acceleration/deceleration (Table 6), indicating the viscous foods are suitable for mastication at uniform acceleration/deceleration.

\section{Conclusion}

The optimal mastication mode and motion laws of different textures of foods were analyzed using the finite element method. The principal stress of brittle foods maximized when the mastication was uniform acceleration/deceleration under the cutting mode. The elastic food showed the largest shear stress during the uniform acceleration/deceleration under the grinding mode. The viscous food showed the largest von Mises stress during the uniform acceleration/deceleration under the grinding mode. These findings can help to design the mandible motion laws of mastication robots for different textures of foods.

\section{References}

[1]. Li Lite, Physical Properties of Foods [M]. Beijing: China Agriculture Press, 2001 (in Chinese).

[2]. Sun Zhonglei, Food Texture Assessment based on Chewing Simulation [D]. Changchun: Jilin University, 2012 (in Chinese).

[3]. Xie Gaopeng. Development and Research of Food Chewing Simulator System[D]. Changchun: Jilin University, 2014 (in Chinese). 
[4]. Liu Aiyang, Beef Auto-control Detection System based on Singlechip Technology [D]. Changchun: Jilin University, 2016 (in Chinese).

[5]. CHRISTIAN M, SOEREN S, KLAUS L, et al. Wear of composite resinveneering materials and enamel in a chewing simulator[J]. Dental Materials, 2007, 23: 1382-1389.

[6]. Li Tonglin, Elastic-Plastic Mechanics (2rd Edition) [M]. Beijing: China University of Geosciences Press, 2016 (in Chinese).

[7]. Li Jinshui, Displacement Equation of Uniformly Accelerated Motion and Application [J]. Journal of Jiangxi Normal University (Natural Science Edition),1979(02): 92-98 (in Chinese).

[8]. Guo Huping. Discussion into Uniformly Accelerated Motion [J]. Science \& Technology Vision, 2014 (15): 136 (in Chinese).

[9]. Liu Zhiyun, Wen Jihua. Measurement and Study on Elastic Modulus of Soybeans [J]. Grain Storage, 2010, 39(03): 27-30 (in Chinese).

[10]. Tang Fuyuan, Feng Jiachang, Cheng Xuduo, Determination and Study on Elastic Modulus of Soybean Seeds [J]. Grain Storage, 2015, 44(05): 6-9 (in Chinese).

[11]. Mao Genwu, Dong Deliang, Yang Ruizheng, Liu Jianwei.Bread Textural Characteristics MeasurementMethods (I) -- Bread Sample Making and Texture Test Methods [J]. Grain Storage, 2010, 39(02): 33-37 (in Chinese).

[12]. Lin Guohui. Application of Zero Trans-Fatty Acids Speciality Fats [D]. Fuzhou University, 2013 (in Chinese).

[13]. Zhou Ying. Aging Characteristics of Different Types of Glutinous Rice Cakes[D]. Jiangnan University,2013 (in Chinese).

[14]. Zhang Zhichao, Zhou Xianqing, Zhang Yurong. Discussion on Measurement Method of Texture Properties of Glutinous Rice Balls [J]. Cereal \& Feed Industry, 2015(10): 32-34+38 (in Chinese). 